\title{
Do Learning Styles Influence Students' Understanding of Chemistry Concepts and Academic Performance in Chemistry?
}

\author{
Dereje Andargie Kidanemariam \\ Institute of Education, Debre Berhan University \\ Ethiopia \\ Harrison I Atagana \\ Institute for Science and Technology Education \\ University of South Africa \\ Temechegn Engida
}

Faculty of Science, Addis Ababa University Addis Ababa, Ethiopia

\section{Doi:10.5901/jesr.2013.v3n5p167}

\begin{abstract}
The study was conducted on 167 grade 11 natural science students in two preparatory schools in Ethiopia. It was designed to predict the extent of variation in academic performance in some fundamental chemical concepts in the topics: Atomic structure \& periodic table, and chemical bonding and structure from variations in Felder-Silverman's learning styles. Data were collected through Amharic version of Felder-Soloman's Index of Learning Style (ILS) questionnaire and chemistry test. The data showed that 1.2\% variation in academic performance in the fundamental concepts in chemistry was linked to the variations in Felder-Silverman's learning styles, and this variation was not statistically significant at $a=0.05$. This implies that the role of learning styles on academic performance on the fundamental concepts considered in this study was not statistically significant. Hence, from this study it can be possible to conclude that the influence of learning styles on academic performance is less likely to be the same across fundamental concepts in chemistry.
\end{abstract}

\section{Introduction}

Current trends in education in general and chemistry education in particular shows that there is emphasis on differentiated instruction that support individual differences such as learning styles (Timothy \& Kimberly, 2010), philosophy and nature of chemistry (Erduran, 2009; Scerri, 2001), and pedagogical content knowledge (Park, Jang, Chen, \& Jung, 2011, Shulman, 1986). However, most of the time these efforts are separate and not well synthesized into a more comprehensive pedagogical content knowledge in chemistry education.

Particularly, the separate research efforts on learning styles in one hand and nature of chemical concepts in the other hand could bring burdens to teachers in their instructional decisions during their chemistry classes. Because, such disintegrated efforts could put chemistry teachers in a confusing scenario of choices.

For instance, according to Danili \& Reid, (2004) and Dalton \& Tasker, (2006) chemical representations can influence instructional presentations. Therefore, at times the representational 
nature of fundamental chemical concepts mismatches to a particular learning style of students the chemistry teacher could fall in to the thrust of choices in instructional decisions. Thus, under this scenario, chemistry teachers' can be challenged by prioritizing different instructional variables in their instructional decisions, i.e. what should be considered first, the types of learning styles or the nature of chemical concepts. And therefore how chemistry teachers' keep the balance of considering learning styles and nature of chemistry in their instructional decisions is remain a niche to be studied.

In this connection, this paper examines the role of learning styles on academic performance in some fundamental concepts of chemistry (see figure 1). As it is presented as a background in the figure below in both schools the chemical concepts were taught in a similar instructional context. Hence, in order to observe the interaction between learning styles and academic performance in chemistry, the current study identified one learning style model and some fundamental concepts in chemistry.

Figure 2. A Concept map: as a tool to visual interactions between Felder-Silverman's learning styles and academic performance on some fundamental chemical concepts.

Felder-Silverman learning styles is the one among more than 70 learning styles (Coffield, Moseley, Hall, \& Ecclestone, 2004), and it is mainly used in chemical engineering education. Since, chemical engineering is similar with chemistry (Johnson, 2006 and McCormack 1938),; Felder-Silverman's learning style is selected for this study.

On the other hand, there are fundamental concepts in chemistry identified by academics in philosophy of chemistry (Caldin, 2002; Schummer, 2003, 2006). For example, pure substances, molecules, molecular structure and aromaticity, atoms and subatomic particles, chemical reaction, affinity, energy, chemical theories, models and laws were some of the fundamental concepts in chemistry identified by Caldin and Schummer. Therefore some of these fundamental chemical concepts which existed in the topics: Atomic structure $\&$ periodic table, and chemical bonding and structure in grade 11 chemistry text book were considered for this study.

The current study was designed to show the link between Felder-Silverman learning styles and academic performance on some fundamental concepts in chemistry and give an insight that needs to be considered for more plausible and possible instructional actions. Therefore research 
question of this study were: How much variance in academic performance on some fundamental concepts in chemistry can be explained by variations in Felder-Silverman learning styles? ; and How well do the learning styles predict academic performance on some fundamental concepts in chemistry among preparatory school natural science students?

\section{Research Method}

Context of the study: This study was conducted on grade 11 natural science students in two preparatory schools (pre-university) in Ethiopia. In Ethiopia, education in preparatory schools is a pre-university education where students attend university introductory courses.

Instructional context of the schools: In both preparatory schools, chemistry is being taught through standardized TV instruction, standardized students' chemistry textbook, and classroom chemistry teacher with same educational rank (all were first degree holders).

\subsection{Sampling Technique}

Populations of the study were 902 natural science students. Therefore, out of 902 students, 167 students were willingly participated in this study. The sample size was estimated by the formula: 50 $+8 \mathrm{k}$ or $104+\mathrm{k}$, k stands for the number of independent variables (Leech, Barrett, \& Morgan (2005). However, to minimize non-response rates, the sample size for this study was 167 students. These 167 participants of the study were selected using a disproportionate stratified sampling technique based on their academic performance in the schools. That is the total elements of the population (902) were first rank ordered based on their academic performance in the school. Thereafter, $25 \%(42)$ of participants were selected from the $1^{\text {st }}$ quartile, $50 \%$ (83) were selected from the interquartile range (Q1-Q3), and the remaining $25 \%(42)$ were selected from the $3^{\text {rd }}$ quartile of the 902 rank ordered population elements.

\subsection{Instruments}

The translated (Amharic) version of Felder-Soloman's Index of Learning Styles was used to identify students learning styles on Felder-Silverman learning styles. Their academic performance on fundamental concepts in the topics: Atomic structure \& periodic table, and chemical bonding and structure were measured using a 22 item chemistry test. The items were constructed based on tables of specification and the following formula:

total number of items per topic $=\frac{\text { number of items in the test } x \text { periods allotted for the topic }}{\text { the total number of periods for topics in which the test is constructed }}$

\section{Result And Discussion}

\subsection{Answering the research questions from the sample statistics}

The mean $(\mathrm{m})$ and standard deviation $(\mathrm{std}$.) of academic performance of sensing learners $(\mathrm{m}=$ 11.90, std. $=3.01)$, intuitive learners $(m=11.7$, std. $=3.15)$, visual learners $(m=11.72$, std. $=$ 3.05), verbal learners $(m=12.06$, std. $=3.02)$, active learners $(m=11.88$, std. $=2.92)$, reflective learners $(m=11.83$, std. $=3.17)$, sequential learners $(m=11.49$, std. $=3.09)$ and global learners $(m=12.04$, std. $=3.01)$ showed only slight difference. These comparisons of means of academic performances of students with different learning styles suggest that their academic performance on the same test constructed from some fundamental concepts in chemistry is approximately the same. These sample statistics shows that academic performance of students with different learning 
styles on fundamental chemical concepts in the topics: Atomic structure \& periodic table, and chemical bonding and structure was comparable. This implies that performance of the sample students on these fundamental concepts in chemistry was not linked to learning style differences.

\subsection{The linear regression model fit and significance test on the data points}

\subsubsection{Regression Model:}

Academic Performance $=\beta_{0}+\beta_{1}$ (Visual/Verbal) $+\beta_{2}$ (Sensing/Intuitive) $+\beta_{3}$ (Active / Reflective) $+\beta_{4}$ (Sequential/Global) $+\epsilon$

The fulfillment of assumptions of multiple regression, such as linearity, normality (using scatter plots), collinearity (using VIF, Tolerance), and normality of residuals (using residual plots) were checked on the data and followed by the regression analysis. The result of the regression analysis that shows the proportion of prediction of academic performance in chemistry in the fundamental concepts that could be explained by learning styles was reported using the coefficient of determination ( $R$ square) (see table 1 ).

Table 1. Test of the Regression model: Model Summary

\begin{tabular}{|c|c|c|c|c|}
\hline Model & R & R Square & Adjusted R Square & Std. Error of the Estimate \\
\hline 1 & $.109^{\mathrm{a}}$ & .012 & -.013 & 3.056 \\
\hline
\end{tabular}

a. Predictors: (Constant), Sequential/Global, Visual/Verbal , Sensing/Intuitive, Active/Reflective

b. Dependent Variable: Performance

As it can be seen from the above table, the coefficient of determination ( $R$ square) is 0.012 . This means that only $1.2 \%$ variations in academic performance on some fundamental concepts in chemistry in the topics: Atomic structure $\&$ periodic table, and chemical bonding and structure can be predicted from variation in learning styles. The remaining $98.8 \%$ of variance in academic performance in chemistry in some fundamental concepts could be explained by variables other than learning styles. Therefore, this implies that the total power of learning styles to explain academic performance on these concepts in chemistry is very small/nearly nil. This $1.2 \%$ variation in academic performance that linked to learning styles was subjected to statistical significant tests (see table 2).

Table 2. Analysis of $A_{N O V A}{ }^{b}$ for testing the statistical significance of the regression model

\begin{tabular}{|cc|c|c|c|c|c|}
\hline & Model & Sum of Squares & Df & Mean Square & F & Sig. \\
\hline \multirow{2}{*}{1} & Regression & 18.155 & 4 & 4.539 & .486 & $.746^{\text {a }}$ \\
& Residual & 1512.396 & 162 & 9.336 & & \\
& Total & 1530.551 & 166 & & & \\
\hline
\end{tabular}

a. Predictors: (Constant), Sequential/Global, Visual/Verbal, Sensing/Intuitive, Active/Reflective

b. Dependent Variable: Performance

As table 2 above indicated that the probability of finding $R$ square of the sample in the population that explain academic performance in chemistry via learning styles is not statistically significant at $a=0.05, \quad F(4,162), p=0.746$. That is predicting academic performance on the fundamental concepts in chemistry in the topics: Atomic structure $\&$ periodic table, and chemical bonding and structure via learning styles was not statistically significant at $a=0.05, F(4,162)=0.486, p=$ 0.746 . This implies that the combination of different learning style dimensions (i.e. the regression model) is less likely to predict students' academic performance on the fundamental chemical 
concepts considered in this study. Therefore, none of the learning style dimensions in this regression model are important predictors of academic performance on the fundamental concepts considered in this study.

According Felder \& Silverman (1988) and Towns (2001), the mismatch between learning styles and instructional methods negatively affects student's academic performance. However, according to the finding of this study and other studies such as Al-Jaroudi (2009), the effect of learning styles on academic performance may not be the same across fundamental concepts in chemistry. For instance Al-Jaroudi (2009) reported that there was not statistically significant relationship between the 4-dimensions of Felder-Silverman learning styles and pre-service elementary teachers' conceptual understanding of chemistry and the nature of matter taught in a simulated learning environment.

From the result of the current study and other similar studies such as Al-J aroudi (2009), it can be possible to conclude that learning styles have not the same influence across different fundamental chemical concepts in chemistry. Hence chemistry teachers need to give relative priority to representational nature of the fundamental concepts and other instructional variables than to worry much on learning styles for teaching fundamental chemical concepts such as atomic structure \& periodic table, and chemical bonding and structure. Moreover, a further study requires to be conducted to see the influence of learning styles on other chemical concepts.

\section{Acknowledgements}

The authors would like to acknowledge Debre Berhan University that funded the study to be conducted and those students who participated in the study. H/Mamo and Debresina preparatory school chemistry teachers and school leaders were supported the research process.

\section{References}

Al-Jaroudi, M. H. (2009). The effect of learning styles and attitudes on preservice elementary teachers' conceptual understanding of chemistry and the nature of matter in a simulation-based learning enviroment. Unpublished An Abstract of a Dissertation Submitted in Partial Fulfillment of the Requirements for the Degree Doctor of Education, University of Northern Iowa.

Caldin, E. F. (2002). The structure of chemistry in relation to the philosophy of science. HYLE-International J ournal for Philosophy of Chemistry, 8(2), 103-121.

Coffield, F., Moseley, D., Hall, E., \& Ecclestone, K. (2004). Learning styles and pedagogy in post-16 learning: A systematic and critical review. London.

Danili, E., \& Reid, N. (2004). Some strategies to improve performance in school chemistry, based on two cognitive factors. Research in Science \& Technological Education, 22(2), 203 - 226.

Erduran, S. (2009). Beyond philosophical confusion: Establishing the role of philosophy of chemistry in chemical education research. Journal of Baltic Science Education, 8(1), 5-14.

Felder, R. M., \& Silverman, L. K. (1988). Learning and teaching styles in engineering education. Engr. Education, 78(7), 674-681

Johnson, A. (2006). Virtual tools: The epistemological and social issues of computer-aided chemical process design. In D. Baird, E. Scerri \& L. McIntyre (Eds.), Philosophy of Chemistry: Synthesis of a New Discipline (Vol. 242, pp. 273-291). Netherlands: Springer.

Leech, N. L., Barrett, K. C., \& Morgan, G. A. (2005). SPSS for intermediate statistics: Use and interpretation (2 ed.). Mahwah, New Jersey: Lawrence Erlbaum Associates, Inc.

McCormack, H. (1938). Instructional relationships between chemistry and chemical engineering. Journal of Chemical Education, 473-475.

Park, S., Jang, J.-Y., Chen, Y.-C., \& Jung, J. (2011). Is pedagogical content knowledge (PCK) necessary for reformed science teaching?: Evidence from an empirical study. Research in Science Education, $41,245-260$.

Scerri, E. R. (2001). The new philosophy of chemistry and its relevance to chemical education. Chemistry Education: Research and Practice in Europe, 2(2), 165-170. 
Tasker, R., \& Dalton, R. (2006). Research into practice: visualisation of the molecular world using animations Chemistry Education Research and Practice, 7(2), 141-159

Timothy, J., Landrum, \& Kimberly, A., McDuffie (2010, January). Learning styles in the age of differentiated instruction. Exceptionality, 6.

Towns, M. H. (2001b). Kolb for chemists: David A. Kolb and experiential learning theory. Journal of Chemical Education, 78, 1107-1116.

Schummer, J. (2003). The philosophy of chemistry. Endeavour 27(1), 37-41.

Schummer, J. (2006). The philosophy of chemistry: From infancy toward maturity. In D. Baird, E. Scerri \& L. Mclntyre (Eds.), Philosophy of Chemistry Synthesis of a New Discipline (Vol. 242, pp. 19-39). The Netherlands: Springer.

Shulman, L. S. (1986). Those who understand: Knowledge growth in teaching. Educational Researcher, 15(2), 4-14. 